\title{
Resilience, sustainability, and complexity in social, environmental, and technical systems
}

\author{
Zachary A. Collier ${ }^{1}$. James H. Lambert ${ }^{1} \cdot$ Igor Linkov $^{2}$
}

Published online: 5 March 2018

๑) Springer Science+Business Media, LLC, part of Springer Nature 2018

The first issue of 2018 in the Springer journal Environment Systems \& Decisions is special in several ways. First, we begin with a special collection of papers on the topic of food security. These papers present novel approaches for understanding and overcoming the challenges of food security in nations of Africa using participatory modeling approaches. An editorial by the special guest editors of the issue follows which provides motivation for the papers and introduces them in greater detail.

Second, this issue presents several response articles to the article by Scholz (2017) providing a thorough overview of Brunswik's theory of probabilistic functionalism. This theory is relevant to the themes and scope of Environment Systems \& Decisions. Brusnwik explored questions of how organisms base their decisions on relevant environmental factors, and helped to motivate research in environmental psychology and coupled human-environmental systems. The original article by Scholz (2017) received ten rigorous peer reviews, resulting in fifty pages of responses. These reviews were developed into short response articles, with a total of eight responses from researchers across diverse topic areas, discussing the details and implications of Brunswik's theory from multiple perspectives (Mumpower 2018; Hoffrage 2018; Susskind 2018; Wilson 2018; Dedeurwaerdere 2018; Mieg 2018; Yarime 2018; Steiner 2018). Following these short articles, Scholz has provided a response to each of the articles (Scholz 2018). The discourse makes a bridge among researchers from (a) judgment and decision making, (b) planning sciences, (c) environmental and sustainability science, and contributes to the theoretical framework

Igor Linkov

Igor.Linkov@usace.army.mil

Zachary A. Collier

zac4nf@virginia.edu

1 University of Virginia, Charlottesville, VA, USA

2 US Army Engineer Research and Development Center, Concord, MA, USA for decision making under uncertainty and complexity. The Editorial Board would like to thank all of the participants for contributing to this scholarly conversation.

Lastly, this issue includes two articles on the topic of resilience, which the Editorial Board has chosen as a yearlong theme for the journal. We will be publishing resiliencethemed articles throughout 2018, and readers are encouraged to submit research contributing to the theory and practice of resilience. In the first paper on resilience, Keenan (2018) models the feasibility of state-run resilience trust funds, designed to support climate change adaptation and resilience investment efforts. This paper highlights the important connection between resilience and finance. Second, Klammler et al. (2018) describe a modeling approach for quantifying the resilience of coupled technological systems. The authors define and characterize two metrics under a regime of stochastic disruptions: critical service deficit and adaptive capacity.

Upcoming issues in 2018 will feature articles on risk assessment and governance of emerging technologies (e.g., nanotechnology, synthetic biology), and general submissions along a wide range of subjects related to the scope of Environment Systems \& Decisions. Manuscript authors are invited to submit traditional research articles, review papers, and perspectives articles for consideration.

\section{References}

Dedeurwaerdere T (2018) From ecological psychology to four varieties of post-positivism in transdisciplinary science. Environ Syst Decis. https://doi.org/10.1007/s10669-017-9663-4

Hoffrage U (2018) From representation via planning to action: an extension of Egon Brunswik's theory of probabilistic functionalism. Environ Syst Decis. https://doi.org/10.1007/s 1066 9-017-9660-7

Keenan JM (2018) Regional resilience trust funds: an exploratory analysis for leveraging insurance surcharges. Environ Syst Decis. https://doi.org/10.1007/s10669-017-9656-3

Klammler H, Rao PSC, Hatfield K (2018) Modeling dynamic resilience in coupled technological-social systems subjected to stochastic 
disturbance regimes. Environ Syst Decis. https://doi.org/10.1007/ s10669-017-9649-2

Mieg HA (2018) A metaphor for taking into account coupled human-environmental systems. Environ Syst Decis. https://doi. org/10.1007/s10669-017-9664-3

Mumpower JL (2018) Comment on Scholz's managing complexity: from visual perception to sustainable transitions - contributions of Brunswik's theory of probabilistic functionalism. Environ Syst Decis. https://doi.org/10.1007/s10669-017-9658-1

Scholz RW (2017) Managing complexity: from visual perception to sustainable transitions-contributions of Brunswik's theory of probabilistic functionalism. Environ Syst Decis 37(4):381-409

Scholz RW (2018) Ways and modes of utilizing Brunswik's theory of probabilistic functionalism: new perspectives for decision and sustainability research? Environ Syst Decis. https://doi.org/10.1007/ s10669-018-9678-5
Steiner G (2018) From probabilistic functionalism to a mental simulation of innovation: by collaboration from vulnerabilities to resilient societal systems. Environ Syst Decis. https://doi.org/10.1007/ s10669-018-9674-9

Susskind L (2018) Comments on "Managing complexity: from visual perception to sustainable transitions. Contributions of Brunswik's theory of probabilistic functionalism". Environ Syst Decis. https ://doi.org/10.1007/s10669-017-9661-6

Wilson RS (2018) Accounting for behavioral responses to environmental cues in complex systems. Environ Syst Decis. https://doi. org/10.1007/s10669-017-9659-0

Yarime M (2018) Learning and open data in sustainability transitions: evolutionary implications of the theory of probabilistic functionalism. Environ Syst Decis. https://doi.org/10.1007/s1066 9-017-9668-z 